\title{
Psychological violence against general practitioners and nurses in Chinese township hospitals: incidence and implications
}

Peng $\mathrm{Li}^{1 \dagger}{ }^{1}$, Kai Xing ${ }^{1 \dagger}$, Hong Qiao ${ }^{2 \dagger}$, Huiying Fang ${ }^{1}$, Hongkun Ma ${ }^{3}$, Mingli Jiao ${ }^{1,4^{*}}$, Yanhua Hao ${ }^{5}$, Ye Li ${ }^{5}$, Libo Liang ${ }^{6}$, Lijun Gao ${ }^{5}$, Zheng Kang ${ }^{5}$, Yu Cui ${ }^{5}$, Hong Sun ${ }^{6}$, Qunhong $\mathrm{Wu}^{5^{*}}$ and Ming Liü ${ }^{7 *}$

\begin{abstract}
Background: International reports indicating that around $10-50 \%$ of health care staff are exposed to violence every year; in certain settings, this rate might reach over $85 \%$. Evidence has shown that people who experience psychological violence are seven times as likely to be victims of physical violence. Although there have been numerous studies on WPV in general hospitals, there is no consensus regarding the current status of psychological violence directed at health care workers in township hospitals in China. The purpose of this study was to estimate the prevalence and the risk factors of psychological violence in Chinese township hospitals.
\end{abstract}

Methods: A retrospective cross-sectional survey of township hospitals general practitioners and general nurses was conducted in Heilongjiang Province, China.Descriptive analyses and binary logistic regression analysis were used to estimated the prevalence and the risk factors of psychological violence.

Results: Regardless of whether the assessment period was the past 12 months, past 36 months, or during their entire career,GPs and nurses reported that verbal abuse was the most common type of psychological violence (28. 05, 30.28, 38.69 and 40.45\%, 43.86, 54.02\%).The main perpetrator was patients' relatives. Most participants responded to violence with "pretend nothing happened", $55.63 \%$ of GPs and $62.64 \%$ of nurses reported that the perpetrator received no punishment. Around $47.62 \%$ of respondents reported that their workplace had no procedures for reporting violence. When workplaces did have a reporting system, $57.73 \%$ knew how to use them. Only 36.98\% had training in managing aggression and violence. General nurses, individuals 35 years or younger, those with higher professional titles and who work in shifts are at greater risk of psychological violence.

Conclusions: Our results indicate a high prevalence of psychological violence in Chinese township hospitals, which can no longer be ignored. Effective measures should be taken to prevent and respond to workplace violence(WPV), especially psychological violence.

Trial registration: (Project Identification Code: HMUIRB20160014), Registered May 10, 2016.

Keywords: Psychological violence, Risk factors, Township hospitals, Workplace violence

\footnotetext{
*Correspondence: minglijiao@126.com; qunhongwu@126.com;

liuming6293@126.com

'Peng Li, Kai Xing and Hong Qiao contributed equally to this work.

'Department of Health Policy and Hospital Management, School of Public

Health, Harbin Medical University, Harbin 150081, China

Department of Social Medicine, School of Public Health, Harbin Medical

University, Harbin 150081, China

${ }^{7}$ Otorhinolaryngology, the 2nd Affiliated Hospital of Harbin Medical

University, Harbin 150081, China

Full list of author information is available at the end of the article
}

(c) The Author(s). 2018 Open Access This article is distributed under the terms of the Creative Commons Attribution 4.0 International License (http://creativecommons.org/licenses/by/4.0/), which permits unrestricted use, distribution, and reproduction in any medium, provided you give appropriate credit to the original author(s) and the source, provide a link to the Creative Commons license, and indicate if changes were made. The Creative Commons Public Domain Dedication waiver (http://creativecommons.org/publicdomain/zero/1.0/) applies to the data made available in this article, unless otherwise stated. 


\section{Background}

Workplace violence (WPV) is defined as "incidents where staff are abused, threatened or assaulted in circumstances related to their work, including commuting to and from work, involving an explicit or implicit challenge to their safety, well-being or health" [1]. Health care workers are 16 times as likely to experience WPV as are other workers, while nurses in particular are three times as likely [2]. WPV against health care workers is common across different countries [3-5], with international reports indicating that around $10-50 \%$ of health care staff are exposed to violence every year; in certain settings, this rate might reach over $85 \%$ [6].

According to the World Health Organization (WHO), WPV can be categorized as physical, psychological (emotional), sexual, and racial [7]. Physical and psychological violence are both common, but psychological violence appears to be more so [8]. Psychological violence can be defined as the intentional act against a person or collective force that results in physical, mental, spiritual, moral, and social harm, including insults, threats, attacks, verbal abuse, and harassment [1]. This definition of psychological violence, created by the $\mathrm{WHO}$, is what we employ in the present study.

More specifically, we operationalize psychological violence as verbal abuse, $\mathrm{Yi}$ Nao, threats, and sexual harassment. Health care workplaces in China are unique given the involvement of Yi Nao, which is literally defined as "health care disturbance." Hesketh and Wu described Yi Nao as gangs consisting "largely of unemployed people with a designated leader. They threaten and assault hospital personnel, damage facilities and equipment, and prevent the normal activities of the hospital." More broadly, Yi Nao can mean any medical or hospital disturbance created by a group of people-such as patients, patients' families, relatives, or Yi Nao gang members hired by patients or their families-who gather at hospitals involved in disputes with patients for actual or perceived medical malpractice. A 2006 survey of 270 tertiary hospitals reported that over $73 \%$ of the participating hospitals had experienced Yi Nao [9]. The aim of Yi Nao is typically to force the hospital to reduce costs or obtain compensation. When financial benefit is their main target, these gangs use extreme acts or criminal behaviors in a devious manner, often avoiding physical violence that would lead to formal punishment under the law; instead, they tend to threaten or abuse health care workers verbally to pressure hospitals into accepting their demands.

Psychological and physical violence among health care workers is associated with decreased job satisfaction, increased occupational strain, and poor patient care outcomes [10-12]. Additionally, WPV negatively influences health care workers' organizational commitment [13]. Moreover, the consequences for the patients and entire facility are serious because the health care workers who perceive themselves at risk of violence are likely to offer poorer quality care and treatment, which in turn has adverse outcomes for patients [14]. Sometimes psychological or verbal abuse has more severe consequences than acts of physical violence.

Evidence has shown that people who experience psychological violence are seven times as likely to be victims of physical violence [15]. Studies set in America in 2004 and 2015 have shown that verbal abuse is the most frequent type of violence reported by physicians and nurses (39-99\%), with physical violence being experienced by only $1-11 \%$ [16-18]. Furthermore, in a study in Pakistan, more than two-thirds of the respondents ( $n$ $=121 / 164,73.8 \%)$ were victims of violence in the preceding 12 months, with verbal abuse $(n=104 / 121,86 \%)$ being the main type of aggression [19]. In Jordan, the prevalence of verbal abuse by patients and visitors was $63.9 \%$, while for physical abuse, $7.2 \%$ was committed by patients and $3.1 \%$ by visitors [20]. Approximately $30 \%$ of hospital staff in central Taiwan reported having experienced only verbal abuse [21]. In both the private and public sectors in Hong Kong, non-physical violence was found to occur more frequently than physical violence; furthermore, there is a reported lack of preparedness of many organizations in dealing with violence [22]. In Italy, around one-tenth of workers have reported some form of physical assault in the workplace, while as many as one-third have been exposed to non-physical violence in the previous year. Nurses and physicians were found to be the most vulnerable occupations [23].

In a past study on hospital violence in China, the incidence of violence in Chinese hospitals reached as high as $95 \%$, indicating that the physical and verbal abuse of medical staff is common [24]. The frequency of psychological violence has also been shown to be higher than that of physical violence-indeed, although violence and aggression towards nurses are frequent, non-physical violence appears far more prevalent $(71.9 \%)$ than physical violence $(7.8 \%)$. Around $24 \%$ of respondents in a Chinese study reported suffering from non-physical violence in relation to Yi Nao [25]. Furthermore, in one survey of the general hospitals in Guangdong Province, the prevalence of psychological violence was $49.12 \%$, while the prevalence of physical violence was $15.36 \%$. Men were found to be more vulnerable to violence, whereas women were more vulnerable to non-physical violence [26].

In China, township hospitals are comprehensive health administration and medical institutions that provide basic rural health services for people living in these towns. They are regarded as the hubs of the rural tertiary health care system. China's new round of healthcare reform and its 12th Five-Year Plan for the medical service system have focused on improving and strengthening township-level 
health facilities. The main goal is to reduce the number of common and frequently occurring diseases. General practitioners (GPs) are central to the health care teams of township hospitals in the future because of the particular status and working characteristics of township hospitals in China [27]. According to the China Health Statistics Yearbook 2013, a report by the Ministry of Health of China [28], China had 37,097 township hospitals, of which there were 996 in Heilongjiang province, and these had 2081 GPs and 3616 registered nurses.

Although there have been numerous studies on WPV in general hospitals, there is no consensus regarding the current status of psychological violence directed at health care workers in township hospitals in China. What is the level of psychological violence in China's rural GPs and nurses? Does it happen to have the same risk factors as other countries? Can we directly cite the other findings to deal with the psychological violence in township hospitals in China? With these questions, we started our research. The specific purposes of this study are to identify the prevalence and severity of psychological violence against GPs and general nurses in township hospitals in Heilongjiang province, northeastern China, and to identify the risk factors contributing to psychological violence in these hospitals.

\section{Methods}

A retrospective cross-sectional survey of general practitioners and general nurses was conducted in Heilongiiang Province, China. In 2012, Heilongjiang had a population of 38.1 million and 996 township hospitals. We randomly selected 90 township hospitals in Heilongjiang Province. Permission to administer the survey was obtained from all 90 township hospitals. The collected data were used to publish an article about physical violence in 2015 [29].

\section{Data collection}

The survey was conducted from September to November 2014, and access was negotiated through the participants' supervisors in every study hospital. An anonymous, self-administered paper questionnaire was distributed to each participant. The questionnaire also included a notification letter and return envelope; the study purpose and rights of the healthcare workers regarding participation were declared in the letter. The participants had 7 days to complete the questionnaire; once they had done so, they placed the completed questionnaire into the return envelope and placed the envelope into a box in the department manager's office to ensure privacy and anonymity. The data collected were secured in a locked room that could only be accessed by research personnel. In this survey, all doctors and nurses $(\mathrm{N}=990)$ of the selected hospitals were approached and a total of 990 questionnaires were distributed .

\section{Questionnaire}

The questionnaire used was developed through a literature review and by modifying a questionnaire developed in 2003 by a joint program of the International Labour Office (ILO), International Council of Nurses, WHO, and Public Services International [30]. First, we formally obtained documented permission to use the questionnaire from the ILO and WHO. It was then translated into Mandarin Chinese and back-translated into English to verify the accuracy of the Mandarin version. Subsequently, the questionnaire was modified to fit our study objectives and the township hospital context in China. For example, Yi Nao was included as part of the items on psychological violence because it is unique to WPV in China. The content validity was determined by a panel of 18 healthcare-related experts throughout China, who were asked to assess the questionnaire in terms of its clarity, relevance, comprehensiveness, and sensitivity to Chinese culture. After revision by the expert committee, the questionnaire was administered to 30 participants as a pre-test. All of these individuals were subsequently excluded from the study. Further modifications were taken as per these individuals' feedback. For all questions, the Cronbach's alpha coefficient was 0.86. The questionnaire was then back translated to English to verify the accuracy of the Mandarin version.

The questionnaire was divided into four sections: (1) the demographic characteristics of the respondents and workplace data; (2) physical violence, including prevalence of physical violence, and the demographic characteristics of perpetrators, attack time, attack tools, and consequences; (3) psychological violence, including prevalence, response of healthcare workers, and workers' methods of dealing with psychological violence; and (4) organizational measures, including incident reporting, supervisor support, and training programs. As this study focused on psychological violence, we used data only from sections "Background, Results, and Discussion". Our questionnaire contains a total of 63 questions and the expected completion time is $10-15 \mathrm{~min}$.

\section{Data analysis}

The data were coded in EpiData, and analyzed using IBM SPSS Statistics 19.0 (IBM Corp., Armonk, NY). Descriptive analyses were used to address the study objectives. Binary logistic regression analysis was used to assess the potential associations between exposure to psychological violence in general (yes/no) and respondents' characteristics, including age, gender, years of experience, educational level, occupation, professional title, and shift work status. Through variable 
selection (criteria: independent variables were entered and excluded from a binary regression model at $p<$ 0.05 ), we entered the variables that meet the requirements into the binary logistic regression model. Odds ratios (ORs) and 95\% confidence intervals (CIs) were calculated; $p<0.05$ was considered statistically significant.

\section{Results}

Of the 840 respondents(response rate $=84.8 \%$ ), 442 were GPs and 398 were general nurses. Only valid responses and percentages were included. Both descriptive and binary logistic regression analyses are presented below.

\section{Demographic characteristics of respondents}

A summary of these characteristics are shown in Table 1.

\section{Prevalence of psychological violence}

The type of violence suffered by those who suffer psychological violence is not exclusive.Due to the fact that some respondents worked less than 36 months in our survey, the number of respondents during the past 36 months was less than 840 . Whether the assessment period was the past 12 months, past 36 months, or during their entire career, GPs and nurses reported that verbal abuse was the most common type of psychological violence (38.69, 54.02\%; 30.28, 43.86 and 28.05\%, $40.45 \%$ ), followed by Yi Nao (23.08, 29.15\%; 17.20, 20.10 and14.93\%, 19.35\%) and threats (20.36, 27.64\%; 16.74, 22.98 and13.80\%, 19.60\%). These are shown in Table 2.

\section{Perpetrators of psychological violence and health care workers' responses and methods of dealing with psychological violence}

Of the 333 victims(during past 12 months), GPs and nurses reported that the main perpetrator were patients' relatives (48.72, 52.54\%), followed by patients (37.82, $32.20 \%)$. Additionally, few colleagues $(0.64,5.09 \%)$ and superiors $(1.28,4.52 \%)$ were reported as the perpetrator. As responses to psychological violence, $50.00 \%$ of the GPs and $37.30 \%$ of the nurses pretended nothing happened, $24.32 \%$ of the GPs and $28.11 \%$ of the nurses took no measures. About more than half of the victims considered these violent incidents as preventable. In the majority of incidents reported by respondents (GPs(57.05\%), nurses(61.58\%)), the perpetrator received no punishment. These are shown in Table 3.

\section{Policy, procedures, and intervention strategies against workplace violence}

Of the 840 respondents,around $47.62 \%$ of respondents $(n=400)$ reported that their workplace did not have procedures for reporting WPV. Where there was a
Table 1 Demographic characteristics of the respondents ( $N=$ 840)

\begin{tabular}{|c|c|c|}
\hline Characteristics & Number & Percent \\
\hline \multicolumn{3}{|l|}{ Gender } \\
\hline Male & 442 & 52.62 \\
\hline Female & 398 & 47.38 \\
\hline \multicolumn{3}{|l|}{ Age } \\
\hline$<35$ & 140 & 16.67 \\
\hline $35-45$ & 426 & 50.71 \\
\hline$>45$ & 274 & 32.62 \\
\hline \multicolumn{3}{|l|}{ Years of experiences } \\
\hline$<10$ & 116 & 13.81 \\
\hline $10-20$ & 394 & 46.90 \\
\hline$>20$ & 330 & 39.29 \\
\hline \multicolumn{3}{|l|}{ Education } \\
\hline Postgraduate & 8 & 0.95 \\
\hline Undergraduate & 380 & 45.24 \\
\hline College & 348 & 41.43 \\
\hline Technical secondary school education and below & 104 & 12.38 \\
\hline \multicolumn{3}{|l|}{ Professional Title } \\
\hline Senior & 170 & 20.24 \\
\hline Intermediate & 410 & 48.81 \\
\hline Junior & 192 & 22.86 \\
\hline No title & 68 & 8.09 \\
\hline \multicolumn{3}{|l|}{ Occupation } \\
\hline General practitioner & 442 & 52.62 \\
\hline General nurse & 398 & 47.38 \\
\hline \multicolumn{3}{|l|}{ Work in shifts } \\
\hline Yes & 385 & 45.83 \\
\hline No & 455 & 54.17 \\
\hline
\end{tabular}

reporting system, only $57.73 \%(n=254)$ of respondents knew how to use it. Furthermore, 55.00\% $(n=462)$ of respondents said that there was no incentive to report workplace violence. Only $39.17 \%$ reported having training in managing aggression and violence, and a total of $54.05 \%$ respondents $(n=454)$ reported that there were no specific measures for dealing with psychological violence in their workplace. All of the rates are presented in Table 4.

\section{Binary logistic regression analysis}

According to the logistic regression analyses, age, occupation, and professional title of respondents were found to have significant associations with exposure to psychological violence in general. More specifically, the odds of psychological violence were lower respondents who were 35 and 45 years $(\mathrm{OR}=0.423,95 \% \mathrm{CI}=0.280,0.639)$, and 45 years and older $(\mathrm{OR}=0.484,95 \% \mathrm{CI}=0.313,0.750)$ 
Table 2 Prevalence of psychological violence

\begin{tabular}{|c|c|c|c|c|c|c|c|c|c|c|c|c|}
\hline \multirow[t]{3}{*}{ Violence type } & \multicolumn{4}{|c|}{ During career } & \multicolumn{4}{|c|}{ During past 36 months } & \multicolumn{4}{|c|}{ During past 12 months } \\
\hline & \multicolumn{2}{|c|}{ GPs (442) } & \multicolumn{2}{|c|}{ Nurses (398) } & \multicolumn{2}{|c|}{ GPs (436) } & \multicolumn{2}{|c|}{ Nurses (383) } & \multicolumn{2}{|c|}{ GPs (442) } & \multicolumn{2}{|c|}{ Nurses (398) } \\
\hline & $\mathrm{N}$ & $\%$ & $\mathrm{~N}$ & $\%$ & $\mathrm{~N}$ & $\%$ & $\mathrm{~N}$ & $\%$ & $\bar{N}$ & $\%$ & $\bar{N}$ & $\%$ \\
\hline Verbal abuse & 171 & 38.69 & 215 & 54.02 & 132 & 30.28 & 168 & 43.86 & 124 & 28.05 & 161 & 40.45 \\
\hline Yi Nao & 102 & 23.08 & 116 & 29.15 & 75 & 17.20 & 77 & 20.10 & 66 & 14.93 & 77 & 19.35 \\
\hline Threat & 90 & 20.36 & 110 & 27.64 & 73 & 16.74 & 88 & 22.98 & 61 & 13.80 & 78 & 19.60 \\
\hline Verbal sexual harassment & 68 & 15.38 & 104 & 26.13 & 48 & 11.01 & 75 & 19.58 & 45 & 10.18 & 57 & 14.32 \\
\hline Sex harassment & 38 & 8.60 & 62 & 15.58 & 32 & 7.34 & 44 & 11.49 & 27 & 6.11 & 37 & 9.30 \\
\hline Any type of violence & 198 & 44.80 & 229 & 57.54 & 164 & 37.61 & 207 & 54.04 & 153 & 34.62 & 180 & 45.23 \\
\hline
\end{tabular}

compared with those who were $<35$ years old. Regarding occupation, compared to GPs, the odds of experiencing psychological violence were higher among general nurses $(\mathrm{OR}=1.787,95 \% \mathrm{CI}=1.330,2.402)$. Respondents with lower professional titles had lower odds of being victims of psychological violence compared to respondents with higher professional titles $(\mathrm{OR}=0.632$, 95\% $\mathrm{CI}=0.541,0.739)$. Finally, the odds of psychological violence were lower among those not working in shifts compared to those engaged in shift work $(\mathrm{OR}=0.613$,

Table 3 Perpetrators of psychological violence and health care workers' response to and method of dealing with psychological violence $(N=333$

\begin{tabular}{|c|c|c|c|c|}
\hline \multirow[b]{2}{*}{ Perpetrator } & \multicolumn{2}{|c|}{ General practitioner } & \multicolumn{2}{|l|}{ Nurse } \\
\hline & $N(156)$ & $\%$ & $N(177)$ & $\%$ \\
\hline Patient & 59 & 37.82 & 57 & 32.20 \\
\hline Patient's relative & 76 & 48.72 & 93 & 52.54 \\
\hline Colleague & 1 & 0.64 & 9 & 5.09 \\
\hline Supervisor & 2 & 1.28 & 8 & 4.52 \\
\hline Others & 18 & 11.54 & 10 & 5.65 \\
\hline Respond to the incident(Multiple choice) & $N(410)$ & $\%$ & $N(497)$ & $\%$ \\
\hline No measures to take & 36 & 24.32 & 52 & 28.11 \\
\hline Pretend nothing happened & 74 & 50.00 & 69 & 37.30 \\
\hline Told the person to stop & 45 & 30.41 & 52 & 27.66 \\
\hline Told friends/family & 66 & 44.59 & 68 & 36.76 \\
\hline Sought counseling & 18 & 12.16 & 19 & 10.11 \\
\hline Told a colleague & 56 & 37.84 & 77 & 41.62 \\
\hline Transferred to another position & 20 & 13.51 & 25 & 16.89 \\
\hline Reported it to a senior staff member & 56 & 37.84 & 77 & 41.62 \\
\hline Completed incident/accident form & 9 & 6.08 & 19 & 10.27 \\
\hline Pursued prosecution & 15 & 10.14 & 16 & 8.64 \\
\hline Completed a compensation claim & 7 & 4.73 & 9 & 4.86 \\
\hline Sought help from the union & 8 & 5.41 & 14 & 7.57 \\
\hline The incident could have been prevented & $N(156)$ & $\%$ & $N(177)$ & $\%$ \\
\hline Yes & 88 & 56.41 & 105 & 59.32 \\
\hline No & 68 & 43.59 & 72 & 40.68 \\
\hline Consequence for the perpetrator & $N(156)$ & $\%$ & $N(177)$ & $\%$ \\
\hline None & 89 & 57.05 & 109 & 61.58 \\
\hline Verbal warning issued by hospital managers & 49 & 31.41 & 56 & 31.64 \\
\hline Stopping treatment & 11 & 7.05 & 7 & 3.96 \\
\hline Reported to police & 7 & 4.49 & 5 & 2.82 \\
\hline
\end{tabular}


Table 4 Policy, procedures, and intervention strategies against workplace violence

\begin{tabular}{|c|c|c|}
\hline & Number & Percent \\
\hline \multicolumn{3}{|c|}{ Procedures for the reporting of violence in your workplace } \\
\hline Reporting only if suffered physical injury & 256 & 30.48 \\
\hline Reporting as long as suffered verbal threat & 184 & 21.90 \\
\hline No & 400 & 47.62 \\
\hline \multicolumn{3}{|c|}{ Know how to use them if have the procedures $(N=440)$} \\
\hline Yes & 254 & 57.73 \\
\hline No & 186 & 42.27 \\
\hline \multicolumn{3}{|l|}{ Encouragement to report workplace violence } \\
\hline Yes & 378 & 45.00 \\
\hline No & 462 & 55.00 \\
\hline \multicolumn{3}{|c|}{ Train in the management of aggression and violence } \\
\hline Yes & 329 & 39.17 \\
\hline No & 500 & 59.52 \\
\hline Data lost & 11 & 1.31 \\
\hline \multicolumn{3}{|c|}{ Specific measures to deal with the psychological violence } \\
\hline Yes & 248 & 29.52 \\
\hline no & 454 & 54.05 \\
\hline Do not know & 138 & 16.43 \\
\hline
\end{tabular}

95\% $\mathrm{CI}=0.455,0.826)$. All results are presented in Table 5.

\section{Discussion}

In terms of the prevalence of psychological violence, our findings are similar to those reported from other countries, which have shown that verbal abuse is the most frequent type of violence [16-24]. Most pressingly, the results indicate that most health care workers suffer from verbal abuse, which suggests that there is an urgent need for policymakers or hospital managers to develop responses.

Arguably the most interesting finding in our study is that health care workers with higher level professional titles had higher odds of psychological violence, which has rarely been found in previous literature. Why is this the case? We suggest several reasons. First, health care workers with higher-level titles are often in contact, during their medical work, with patients or their families who are seriously ill. As such, when the effects of their treatment fall short of the patients' and families' expectations, these parties might blame the doctors, thus further triggering psychological violence. Second, those healthcare workers with higher titles might be involved in larger health care issues and medical disputes than those with lower titles in their daily work. Thus, they would have a greater likelihood of suffering from psychological violence.

General nurses were most exposed to psychological violence. First of all,nurses are more likely to encounter aggressive behavior because they tend to communicate and interact more with patients and their families than GPs. Second, according to the 2013 China Health Statistics Yearbook, the number of health workers in township hospitals in Heilongjiang Province in 2013 reached 2.26: 1 [28].This means that nurses in township hospitals have more work to do in their day-to-day work than doctors do. High workloads make them unable to fully meet the service needs of patients during the limited working hours, but also more prone to work under high pressure errors, resulting in patient dissatisfaction with the work of nurses. Furthermore, they frequently work at nights, have higher stress and workloads, and lack good management policies and support [31-34]. WPV has been found to be associated with stress and work strain; this connection is believed to be circular, as work strain and stress can be causes of WPV, which in turn leads to greater work strain and stress. Worse still, the increased negative stress leads to a greater likelihood of not only WPV, but also burnout, suicide, and even murder. Notably, the directional relationship of stress to violence is usually mediated by various factors, while the relationship of violence to stress is direct $[35,36]$. Our study also found that health care workers who work in shifts show greater odds of psychological violence. We suspect that stress is implicated in this result as well: namely, those who often work in shifts might have higher stress levels and workloads, thus increasing the likelihood of WPV.

The logistic regression analysis also revealed that respondents of younger age had greater odds of experiencing psychological violence. Other studies have provided evidence that as health care workers' age increases, the frequency of experiencing violence decreases [29, 37, 38].

In our study, we found some risk factors for psychosocial violence among healthcare workers in township hospitals in China.However, in the case of multiple risk factors clustering in one person (for example, a younger nurse with a shift experience a greater chance of psychological violence than a township health worker with only one risk factor experiences psychological violence.Interestingly, in practice, older doctors tend to have a higher professional title. In our study, doctors with high professional titles were found to have a higher risk of psychological violence. Therefore, in this case, the probability of their being subjected to psychological violence remains to be studied.

The present study has shown that patients' families are the main source of psychological violence. Previous studies have similarly reported that 64.52 to $98.8 \%$ of aggressors are patients' relatives [39-41]. This might be because, first, patients' relatives tend to experience considerable stress due to economic, spiritual, and even social factors related to their family member's illnesses. Furthermore, when they have high expectations for treatment and lack sufficient understanding of disease severity, they might feel increasingly helplessness and 
Table 5 Risk factors associated with psychological violence among GPs and general nurses in township hospitals in Heilongjiang province (binary logistic regression model results)

\begin{tabular}{|c|c|c|c|c|c|c|c|c|c|c|c|c|c|}
\hline \multirow[t]{4}{*}{ Characteristics } & & \multicolumn{12}{|c|}{ Psychological violence $(n=333)$} \\
\hline & & \multicolumn{6}{|c|}{ Univariate analysis } & \multicolumn{3}{|c|}{$\begin{array}{l}\text { logistic regression } \\
\text { (initial model) }\end{array}$} & \multicolumn{3}{|c|}{$\begin{array}{l}\text { logistic regression } \\
\text { (final model) }\end{array}$} \\
\hline & & \multicolumn{2}{|l|}{$\overline{Y e s}$} & \multicolumn{2}{|l|}{ No } & \multirow[t]{2}{*}{$x^{2}$} & \multirow[t]{2}{*}{$p$} & \multirow[t]{2}{*}{$\overline{O R s}$} & \multirow[t]{2}{*}{$95 \% \mathrm{Cls}$} & \multirow[t]{2}{*}{$p$} & \multirow[t]{2}{*}{$\overline{O R S}$} & \multirow[t]{2}{*}{$95 \% \mathrm{Cls}$} & \multirow[t]{2}{*}{$p$} \\
\hline & & $n$ & $\%$ & $n$ & $\%$ & & & & & & & & \\
\hline \multirow[t]{2}{*}{ Gender } & Male & 200 & 45.25 & 242 & 54.75 & 0.000 & 0.995 & 1.00 & Reference & & & & \\
\hline & Female & 180 & 45.23 & 218 & 54.77 & & & 0.809 & $(0.586,1.116)$ & 0.379 & & & \\
\hline \multirow[t]{3}{*}{ Age } & $<35$ & 73 & 51.41 & 69 & 48.59 & 9.922 & 0.007 & 1.00 & Reference & & 1.00 & Reference & \\
\hline & $35-45$ & 156 & 36.97 & 266 & 63.03 & & & 0.423 & $\begin{array}{l}(0.280 \\
0.639)\end{array}$ & $<0.001$ & 0.473 & $\begin{array}{l}(0.283, \\
0.832)\end{array}$ & 0.006 \\
\hline & $>45$ & 104 & 37.68 & 172 & 62.32 & & & 0.484 & $\begin{array}{l}(0.313 \\
0.750)\end{array}$ & 0.001 & 0.544 & $\begin{array}{l}(0.333, \\
0.956)\end{array}$ & 0.009 \\
\hline \multirow{3}{*}{$\begin{array}{l}\text { Years of } \\
\text { experiences }\end{array}$} & $<10$ & 49 & 41.53 & 69 & 58.47 & 1.160 & 0.560 & 1.00 & Reference & & & & \\
\hline & $10-20$ & 147 & 37.69 & 243 & 62.31 & & & 0.640 & $(0.380,1.079)$ & 0.094 & & & \\
\hline & $>20$ & 137 & 41.27 & 195 & 58.73 & & & 0.445 & $\begin{array}{l}(0.024- \\
8.187)\end{array}$ & 0.498 & & & \\
\hline \multirow[t]{4}{*}{ Education } & Postgraduate & 4 & 50.00 & 4 & 50.00 & 14.057 & 0.003 & 1.00 & Reference & & & & \\
\hline & Undergraduate & 135 & 35.71 & 243 & 64.29 & & & 0.645 & $(0.146,2.848)$ & 0.562 & & & \\
\hline & College & 158 & 45.14 & 192 & 54.86 & & & 1.136 & $(0.260,4.969)$ & 0.866 & & & \\
\hline & $\begin{array}{l}\text { Technical secondary } \\
\text { school education } \\
\text { and below }\end{array}$ & 28 & 26.92 & 76 & 73.08 & & & 0.708 & $(0.156,3.215)$ & 0.655 & & & \\
\hline \multirow[t]{2}{*}{ Occupation } & General Practitioner & 156 & 35.29 & 286 & 64.71 & 7.373 & 0.007 & 1.00 & Reference & & 1.00 & Reference & \\
\hline & General nurse & 177 & 44.47 & 221 & 55.53 & & & 1.787 & $\begin{array}{l}(1.330 \\
2.402)\end{array}$ & 0.001 & 1.832 & $\begin{array}{l}(1.520, \\
2.603)\end{array}$ & 0.001 \\
\hline \multirow[t]{2}{*}{ Professional title } & Senior & 102 & 58.62 & 72 & 41.38 & 33.033 & $<0.001$ & 1.00 & Reference & & 1.00 & Reference & \\
\hline & Intermediate/Junior/No title & 231 & 34.68 & 435 & 65.32 & & & 0.632 & $\begin{array}{l}(0.541 \\
0.739)\end{array}$ & $<0.001$ & 0.680 & $\begin{array}{l}(0.571, \\
0.810)\end{array}$ & $<0.001$ \\
\hline \multirow[t]{2}{*}{ Work in shifts } & Yes & 169 & 43.90 & 216 & 56.10 & 5.374 & 0.020 & 1.00 & Reference & & 1.00 & Reference & \\
\hline & No & 164 & 36.04 & 291 & 63.96 & & & 0.613 & $(0.455,0.826)$ & 0.001 & 0.675 & $(0.506,0.901)$ & 0.008 \\
\hline
\end{tabular}

become discontented with staff, thus leading them to commit WPV [42]. Second, there might be miscommunication between patients' families and health care staff, especially nurses, which suggests the necessity of improving the quantity and quality of nurses' communication with patients and families.

In conclusion, through our research, we found some risk factors for health care workers who are more susceptible to psotection of these groups. For example, first of all, it is necessary to have sufficient financial support and safety facilities, in particular to strengthen the human resources provision of rural hospitals. Second, when it comes to helping township hospitals in tertiary hospitals in cities in China, the content of psychological violence prevention and treatment can be increased. In addition, in view of the patient's sexual harassment of female health workers, we believe that early education and prevention are effective ways to solve such problems. For this reason, medical undergraduate and young doctors should train and inform about sexual harassment and how to deal with sexual harassment [43].

Notably, $55.63 \%$ of GPs and $62.64 \%$ of nurses referred that the perpetrators did not receive any kind of punishment. This should be a matter of concern, especially because evidence shows that WPV usually results in shortand long-term effects on victims' physical and psychological state, and even their professional performance $[44,45]$. Other studies [46, 47] have shown that individuals who experience psychological violence, and endure feelings/ symptoms over time, might be at risk for adverse mental health outcomes such as acute stress disorder or post-traumatic stress disorder.

Why does most of the psychological violence of health care workers have a lower reporting rate? One of the reasons for underreporting is the assessment of the seriousness of health care workers about the violence they have suffered. If the victim considers that some issues of psychological violence are not particularly serious, they may 
not report. Ownship health workers may treat less-severe psychological violence (such as light verbal abuse) as part of the job and will not report such incidents [48]. If the victims thought that the problem was not serious, they might not report it. Second, this finding might be related to the fact that most perpetrators did not receive any kind of punishment. In other words, workers might have thought that responding to the incident would be of no use. Finally, more than half of the respondents said that their hospitals did not have specific measures for dealing with psychological violence and did not encourage the reporting of WPV in our study, which might have led victims to choose to remain silent. To solve this issue, a priority for hospital leaders would be paying greater attention to psychological violence and learning of the serious of the consequences for health care workers' physical and mental health as well as the functioning of the entire health system.

The majority of respondents in our study reported that there were no procedures for reporting violence in their workplace; when there were such procedures, many only reported incidents of physical violence. Although the results were not significant, having procedures for reporting violence is considered a protective factor for WPV by many researchers. However, only having procedures for reporting violence is insufficient; hospital leaders must also encourage employees to report incidents of WPV. The attention of hospital leaders is an important prerequisite of dealing with violence. However, one consequence of a failure to report WPV is an absence of evidence to help health policymakers become aware of WPV.

Only $39.17 \%$ of respondents reported having training in the management of aggression and violence in our study. This suggests that training must be sustained at the organizational level in order to prevent and respond to psychological violence. From a management perspective, first, hospital managers should organize medical staff to convene an exchange of medical violence experiences. By pooling experience in this way, hospitals could ensure the early prevention and reduce the harm caused by violence. Second, these managers should assess current riot control measures in their respective health facilities. Finally, they might refer to violence prevention research in other preventive health care institutions [49-52], and to train staff to prevent and respond to hospital violence, such as by teaching emotional conditioning skills to help staff manage patients' or families' negative emotions (e.g., medical anger) and or interpersonal communication skills to promote more effective communication between patients and staff.

\section{Limitations}

The present study has several limitations. First, because of time and resource restrictions, our study was limited to 90 purposively selected township hospitals in a single province in China. Therefore, we cannot generalize our findings to all of the township hospitals in Heilongjiang province or all of China. However, our findings might provide a guide for further research on WPV in Chinese township hospitals. Second, this study was retrospective and involved questionnaires that required respondents to recall events occurring in the past 12 months. This makes the data subject to recall bias.

\section{Conclusions}

Township hospitals are important primary health care institutions in China, and it is becoming increasingly important to attend to WPV in these hospitals. The results of this study indicate that there is a high prevalence of psychological violence against health care workers in such hospitals. Considering that more than half of respondents did not report the violence, it is important to establish appropriate reporting systems and provide training programs for health professionals in order to prevent and manage WPV, especially psychological violence. This study found some risk factors of psychological violence among general practitioners and nurses in township hospitals in Heilongjiang Province, which provided a good reference for our policy making and the management of township hospitals to prevent psychological violence in hospitals.However, our extrapolation of our results also requires increasing the sample size or taking into account the specific circumstances of each region. For future research, we would like to assess the effectiveness of current measures to prevent and resolve violence in Chinese township hospitals.

\section{Abbreviations}

GPs: General practitioners; WHO: World Health Organization; WPV: Workplace violence

\section{Acknowledgments}

The authors would like to thank all of the study participants for their detailed information. We are also very grateful to the Institutional Review Board of Harbin Medical University for their ethical approval. We further thank Dr. Jiao Mingli for her guidance in writing the manuscript.

\section{Funding}

This study was funded by the Natural Science Foundation of China (71273002, 71473064); Education Department of Heilongjiang Province (JGXM-HLJ-2014087, education reform project 349); Talent Cultivation Program of Heilongjiang Province (1252-NCET-020); China Postdoctoral Research Fund First Aid and Special Aid (2015 M570211, 2016 T90181).

\section{Availability of data and materials}

The collected data were used to publish an article about physical violence in 2015 in PLOS ONE.

\section{Authors' contributions}

$P L, K X$ and $H Q$ drafted the manuscript; $M J$ designed the study; $Y H, L G, L L, H S$ and ZK collected the data; MJ, QW, HQ and YL analyzed the data; HM, ML, YC and HF contributed to the manuscript's revision. All authors approved the final manuscript for publication.

Ethics approval and consent to participate

Ethical approval was granted by the Institutional Review Board of Harbin Medical University before data collection commenced, and all procedures 
were approved by each study hospital. All participants gave their informed content to participate (Project Identification Code: HMUIRB20160014).

\section{Consent for publication}

This study has obtained consent to publish from the participants to report individual data.

\section{Competing interests}

The authors declare that they have no competing interests.

\section{Publisher's Note}

Springer Nature remains neutral with regard to jurisdictional claims in published maps and institutional affiliations.

\section{Author details}

${ }^{1}$ Department of Health Policy and Hospital Management, School of Public Health, Harbin Medical University, Harbin 150081, China. ${ }^{2}$ Endocrine and Metabolic Diseases, the 2nd Affiliated Hospital of Harbin Medical University, Harbin 150081, China. ${ }^{3}$ Department of Health Management, Harbin Medical University, Harbin 150081, China. ${ }^{4}$ Institute of Quantitative and Technical Economics, Chinese Academy of Social Science, Beijing 100000, China. ${ }^{5}$ Department of Social Medicine, School of Public Health, Harbin Medical University, Harbin 150081, China. ${ }^{6}$ Department of Medical Demography, School of Public Health, Harbin Medical University, Harbin 150081, China. ${ }^{7}$ Otorhinolaryngology, the 2nd Affiliated Hospital of Harbin Medical University, Harbin 150081, China.

Received: 13 April 2017 Accepted: 21 May 2018 Published online: 05 June 2018

\section{References}

1. Krug EG, Dahlberg LL, Mercy JA, Zwi AB, Lozano R. World report on violence and health. Geneva: World Health Organization; 2002.

2. Smith-Pittman MH, Mckoy YD. Workplace violence in healthcare environments. Nurs Forum. 1999:34:5-13.

3. Esmaeilpour mscn bscn rn M, Salsali phd msen bsen rn M, Ahmadi phd mscn bscn rn F. Workplace violence against Iranian nurses working in emergency departments. Int Nurs Rev. 2011;58(1):130

4. Shiao JS, Tseng Y, Hsieh YT, Hsieh YT, Hsieh YT, Guo YL. Assaults against nurses of general and psychiatric hospitals in Taiwan. Int Arch Occup Environ Health. 2010;83:823-32.

5. Shoghi M, Sanjari M, Shirazi F, Heidari S, Salemi S, Workplace Violence MG. Abuse against nurses in hospitals in Iran. Asian Nurs Res (Korean Soc Nurs Sci). 2008:2:184-93.

6. Kwok R, Law Y, Li K, Ng Y, Cheung M, Fung V, et al. Prevalence of workplace violence against nurses in Hong Kong. Hong Kong Med J. 2006:12:6-9.

7. Ray MM. The dark side of the job: violence in the emergency department. J Emerg Nurs. 2007:33(3):257-61.

8. Lau JBC, Magarey J, McCutcheon H. Violence in the emergency department: a literature review. Australian Emerg Nurs J. 2004;7(2):27-37.

9. Cai W, Deng $\mathrm{L}$, Liu $\mathrm{M}$, et al. Antecedents of medical workplace violence in South China. J Interpers Violence. 2011;26:312-27.

10. Zampieron A, Galeazzo M, Turra S, Buja A. Perceived aggression towards nurses: study in two Italian health institutions. J Clin Nurs. 2010;19:2329-41.

11. Gates D, Fitzwater E, Succop P. Predicting assaults against caregivers in nursing homes. Issues Ment Health Nurs. 2003;24:775-93.

12. Farrell G, Cubit K. Nurses under threat: a comparison of content of 28 aggression management programs. Int J Mental Health Nurs. 2005;14:44-53.

13. Camerino D, Estryn-Behar M, Conway PM, van Der Heijden B, Hasselhorn HM. Work-related factors and violence among nursing staff in the European NEXT study: a longitudinal cohort study. Int J Nurs St. 2008;45(1):35-50.

14. Roche M, Diers D, Duffield C, Catling-Paul C. Violence toward nurses, the work environment, and patient outcomes. J Nurs Scholarship. 2010;42:13-22.

15. Lanza ML, Zeiss RA, Rierdan J. Non-physical violence: a risk factor for physical violence in health care settings. AAOHN J. 2006;54(9):397-402.

16. Pompeii LA, Schoenfisch AL, Lipscomb HJ, Dement JM, Smith CD, Upadhyaya M. Physical assault, physical threat, and verbal abuse perpetrated against hospital workers by patients or visitors in six U.S. hospitals. Am J Ind Med. 2015;58:1194-204.
17. Gerberich SG, Church TR, McGovern PM, et al. An epidemiological study of themagnitude and consequences of work related violence: the Minnesota nurses' study. Occup Environ Med. 2004;61:495-503.

18. Kelly EL, Subica AM, Fulginiti A, Brekke JS, Novaco RWA. Cross-sectional survey of factors related to inpatient assault of staff in a forensic psychiatric hospital. J Adv Nurs. 2015;71:1110-22.

19. Imran N. Aggression and violence towards medical doctors and nurses in a public health care facility in Lahore, Pakistan: a preliminary investigation. Khyber medical university Journal. 2013;5:179-18.

20. Al-Ali NM, Al Fl, Al-Niarat TF. The impact of training program on nurses' attitudes toward workplace violence in Jordan. Applied Nursing Research Anr. 2016:30:83.

21. Hsieh HF, Chang SC, Wang HH. The relationships among personality, social support, and resilience of abused nurses at emergency room and psychiatric Ward in Taiwan[J]. Women \& Health. 2016;57(1):40-51.

22. Lo TW, Chappell D, Kwok SI, et al. Workplace violence in Hong Kong, China: nature, impact, and preparedness. Int J Offender Ther Comp Criminol. 2012; 56(6):955-75.

23. Magnavita N, Heponiemi T. Violence towards health care workers in a public health Care Facility in Italy: a repeated cross-sectional study. BMC Health Serv Res. 2012;12(1):127-39.

24. Jia $X$, Zhou $H$, Zhao $Y$, et al. Investigation on violence and injury in hospitals in China from 2003 to 2012. Chinese Hospital. 2014;3:1-3.

25. Jiao M, Ning N, Li Y, et al. Workplace violenceagainst nurses in Chinese hospitals: a cross-sectionalsurvey. BMJ Open. 2015;5:e006719.

26. Chen Z, Wang S. Analysis on the epidemiological features and risk factors of hospiatl workplace violence in Guangzhou. Chin J epidemiol. 2004;25:No 1. (In Chinese)

27. Zhao X, Huang H, Li L, Wang Y, Chen SJ. The reasons and countermeasures of lack of general practitioners in the township health hospitals in China. School Health Manag Educ. 2014;17(25):2926-9.

28. China Statistical Yearbook of Health Care. (2013). Available from http://www moh.gov.cn. Accessed 10 July 2014.

29. Xing K, Jiao M, Ma H, Qiao H, Hao Y, Li Y, et al. Physical violence against general practitioners and nurses in Chinese township hospitals: a crosssectional survey. PLoS One. 2015;10(11):e0142954.

30. ILO/ICN/WHO/PSI. Framwork guidelined for affressing workplace violence in health sector. 2002.

31. Teymourzadeh E, Rashidian A, Arab M, Akbari-Sari A, Hakimzadeh SM Nurses exposure to workplace violence in a large teaching. Int J Health Policy Manag. 2014;3:301-5.

32. Oztunc $\mathrm{G}$. Examination of incidents of workplace verbal abuse against nurses. J Nurs Care Qual. 2006;21:360.

33. Khademi M, Mohammadi $\mathrm{E}$, Vanaki Z. Nurses' experiences of violation of their dignity. Nurs Ethics. 2012;19:328-40.

34. Khademloo M, Moonesi FS, Gholizade $\mathrm{H}$. Health care violence and abuse towards nurses in hospitals in north of Iran. Glob J Health Sci. 2013:5:211.

35. Gates DM, Gillespie GL, Succop P. Violence against nurses and its impact on stress and productivity. Nurs Econ. 2011;29:59-66.

36. Magnavita N. Workplace violence and occupational stress in healthcare workers: a chicken-and-egg situation —results of a 6-year follow-up study. J Nurs Scholarsh. 2014:46:366-76.

37. Kamchuchat C, Chongsuvivatwong V, Oncheunjit S, Yip TW, Sangthong R. Workplace violence directed at nursing staff at a general hospital in southern Thailand. J Occup Health. 2008;50(2):201-7.

38. Algwaiz WM, Alghanim SA. Violence exposure among health care professionals in Saudi public hospitals:a preliminary investigation. Saudi Med J. 2012;33:76-82

39. Rafati Rahimzadeh M, Zabihi A, Verbal HSJ. Physical violence on nurses in hospitals of Babol University of Medical Sciences. HAYAT. 2011;17(2):5-11.

40. Talas MS, Kocaoz S, Akguc SA. Survey of violence against staff working in the emergency department in Ankara, Turkey. Asian Nurs Res (Korean Soc Nurs Sci). 2011:5(4):197-203.

41. Aghilinejad M, Nojomi M, Mehdi S, Mohammad S. Study of prevalence of violence against nurses and related factors. Razi. J Med Sci. 2011;18(86):49-58.

42. Zuhui C, Shengyong W, Yecheng L, Chunxia J. Analysis on the epidemiological features and risk factors of hospital workplace violence in Guangzhou. Chin. J Epidemiol. 2004;25(1):3-5.

43. Tolhurst $H$, Baker L, Murray $G$, et al. Rural general practitioner experience of work-related violence in Australia. Aust J Rural Health. 2003;11(5):231-6.

44. Erkol H, Gökdoğan MR, Erkol Z, Boz B. Aggression and violence towards health care providers-a problem in Turkey? J Forensic Legal Med. 2007;14:423-8. 
45. Gillespie GL, Gates DM, Miller M, Howard PK. Workplace violence in healthcare settings: risk factors and protective strategies. Rehabil Nurs. 2010;35:177-84

46. Ryan JA, Poster EC. The assaulted nurse: short-term and long-term responses. Arch Psychiatr Nurs. 1989:3:323-31.

47. Levin PF, Hewitt JB, Misner ST. Insights of nurses about assault in hospitalbased emergency departments. Image J Nurs Sch. 1998;30:249-54.

48. Rn MBN, Rn AHB, Rn SFB. Factors affecting Israeli nurses' reports of violence perpetrated against them in the workplace: a test of the theory of planned behaviour. Int J Nurs Pract. 2011;17(2):141-50.

49. Health and Safety Commission Advisory Committee. Violence and aggression to staff in the health service. London: HSC Books; 1997.

50. Feng Z, Li T. Guideline for preventing violence at hospitals in China (20112012). Am J Med Qual. 2012;28(2):169-71.

51. Leon-Perez JM, Notelaers G, Leon-Rubio JM. Assessing the effectiveness of conflict management training in a health sector organization: evidence from subjective and objective indicators. Eur J Work Organ Psy. 2016;25(1): 1-12. https://doi.org/10.1080/1359432X.2015.1010520

52. Phillips JP. Workplace violence against health Care Workers in the United States. N Engl J Med. 2016:374(17):1661-9.

\section{Ready to submit your research? Choose BMC and benefit from:}

- fast, convenient online submission

- thorough peer review by experienced researchers in your field

- rapid publication on acceptance

- support for research data, including large and complex data types

- gold Open Access which fosters wider collaboration and increased citations

- maximum visibility for your research: over $100 \mathrm{M}$ website views per year

At BMC, research is always in progress.

Learn more biomedcentral.com/submissions 